\title{
Pneumoconiosis and byssinosis
}

\author{
D. C. F. MUIR \\ Institute of Occupational Medicine, Roxburgh Place, Edinburgh, EH8 9SU
}

On 1 August 1968 the Minister of Social Security referred the following question to the Industrial Injuries Advisory Council for consideration and advice:

Whether in the light of experience and current knowledge any adjustment should be made in the terms of the definition of pneumoconiosis in section 58 (3) of the National Insurance (Industrial Injuries) Act 1965; and whether any and, if so, what special provision should be made for disablement due to other respiratory conditions found in the presence of such pneumoconiosis to be taken into account in assessing the extent of disablement due to the disease.

The Council referred the question to their Industrial Diseases Sub-Committee for detailed consideration. The Sub-Committee met on 29 occasions and their report was submitted to the Secretary of State for Social Services on 27 June 1973. Its publication was followed by heated controversy in the medical and national press. This gradually subsided following an announcement by the Secretary of State in the House of Commons that there would be no change in the regulations concerning compensation for pneumoconiosis.

The report names those organizations and persons from whom evidence was received. The list includes many of the recognized experts in the field in this country, together with representatives of employees, management, and other interested groups. How is it possible for such a plethora of informed evidence to be received, for conclusions and recommendations to be made on this evidence, and for these to be promptly rejected? If there were general agreement among the medical profession as to the 'facts' about pneumoconiosis it is probable that the Secretary of State's decision would be regarded as being purely political. If there is any agreement among physicians, however, it must surely be that we appear to be at loggerheads over the question of pneumoconiosis in general and of related disability in particular.

The less controversial aspects of the report should perhaps be mentioned first in order to clear the way for a review of its more fundamental features. It is well written and has concise and clear explanations of the problems considered. The historical background is reviewed in detail, and there is an excellent description of the work of the Pneumoconiosis Medical Panels. There is a great deal of information in the report which is not available in textbooks of occupational medicine, and it should be essential reading for all who have an interest in this field. The summary and conclusions are short and explicit.

Some of the recommendations represent a tidying-up operation so that the regulations conform more closely to modern medical opinion. Such an example is given by a suggested new definition of pneumoconiosis. The report makes it clear, however, that the diagnostic practice of the Pneumoconiosis Medical Panels is regarded as working well and that a new definition is not intenced to imply any variation in current standards. In the case of asbestosis the report suggests a change that appears eminently sensible. If inhaled asbestos causes fibrosis of the lungs, then the patient is considered as having pneumoconiosis. If those same fibres cause fibrosis of the pleura alone then he is not. Irrespective of the presence or absence of disability associated with pleural plaques, present regulations exclude further consideration because the law is based on fibrosis of the lungs. The report recommends that this anomaly be removed by including the visceral and parietal pleura in the term 'lung'. Anatomists are unlikely to quibble too much over this small adjustment. No change is suggested in the present provisions for disablement due to other respiratory conditions found in the presence of pneumoconiosis or in special hardship allowances. The potential of the Pneumo- 
coniosis Medical Panels as a focus for research is emphasized and the possible disadvantages of isolation from the main stream of medical practice and thought in the National Health Service are noted. The reality of professional isolation of this sort is, of course, present in other branches of occupational medicine and is undoubtedly bad for all concerned, whether within the National Health Service or not. The Council hope that the panels will maintain and develop their contacts with their medical colleagues in the National Health Service.

The real meat of the report is contained in the recommendations that the new definition of pneumoconiosis should continue to exclude bronchitis and emphysema and that a diagnosis of pneumoconiosis should not automatically imply eligibility for benefit.

The Committee considered that bronchitis and emphysema, in the absence of pneumoconiosis as at present defined, was excluded from their enquiry by their explicit terms of reference. Where the two coexist the present regulations work well and allow disability from bronchitis to be taken into account. However, what is to be done about the miner who is severely disabled by emphysema but whose chest radiograph shows no evidence of small rounded opacities? Because of the controversy surrounding this subject, details are given of the reasons why such a man is not eligible for compensation under present regulations. The problem is traced back to the Industrial Injuries Act (1946) which continued the precedent of the Workers' Compensation Act of 1919 and of later Acts whereby the State paid special compensation for respiratory disability if this was contracted as a result of certain defined occupations. No such special payment was available for other respiratory disabilities. It is pointed out in the report that, for any disease to be prescribed for the purposes of this benefit, the Secretary of State must first be satisfied that the disease:

(a) ought to be treated, having regard to its causes and incidence and any other relevant considerations, as a risk of occupation and not as a risk common to all persons; and

(b) is such that, in the absence of special circumstances, the attribution of particular cases to the nature of the employment can be established or presumed with reasonable certainty.

Since bronchitis is so widespread in this country as a result of cigarette smoking and of other pollutants, it is impossible at present to attribute an individual case occurring in an industry such as coal mining to an occupational cause. This apparently remains so even if it is known that bronchitis is common in dusty industries. The report points out that an occupational origin for bronchitis in an individual would be acceptable if the incidence of the disease in the industry in which he was employed was exceptionally high. This is not so in any occupation 3 at present. The general requirements for the prescription of an industrial disease would also, at present, exclude any attempt to enlarge the concept of pneumoconiosis of coalworkers to include pulmonary dysfunction in the absence of pathognomonic radiological abnormalities. Suppose the present definition 'fibrosis of the lungs due to silica dust, asbestos dust or other dust, and includes the condition of the lungs known as dust-reticulation' were extended to include fibrosis of the small airways or lung which resulted in emphysema. It may be argued that this is exactly the situation in byssinosis, for example. The similarity is misleading, however, since byssinosis can be diagnosed by an accurate history, and thereby any ventilatory defect can be definitely and finally attributed to an industrial cause. No similar specific and identifiable respiratory disease in coalworkers is known at present other than that associated with the radiological changes widely recognized as being diagnostic of dust disease of the lung. Any functional disorder of the lungs in a coal miner whose chest radiograph did not show typical round opacities could not therefore fulfil the two general requirements for it to be accepted as occupational in origin. The Committee hold out no hope that it will be possible in the future to distinguish the effects of coal mine dust from the effects of cigarette smoke and of general air pollution other than by means of radiology. They consider that a close watch should be kept on research results in case some progress towards such a distinction could be made. One member of the Committee evidently felt like $\mathrm{Mr}$. Bumble. He issued a minority report suggesting that, if this was the meaning of the original Acts, then it was time for a fundamental review of the rules governing the prescription of diseases for purposes of compensation.

The second contentious matter, and the one which generated most heat, concerned the threshold of disease for benefit purposes. The report gives considerable space to this problem and reviews the development of knowledge concerning the relationship between pneumoconiosis and disability. The legal background is relatively straightforward. Since 1954 pneumoconiosis has been treated in the same way as other prescribed diseases and as injuries caused by accident. Under these rules, a disease, once diagnosed, is assessed with regard to the disability it causes. A pension or compensation is payable if disability is considered to be $1 \%$ or more. For administrative reasons assessments are made only in steps of $10 \%$ and the minimum pension payable is thus $10 \%$.

The effect of the present regulations is that all men in whom a definite diagnosis of pneumoconiosis is made receive a pension since the view is taken that this must indicate disability of at least $1 \%$. The practice of the Panels is to make such a diagnosis if 
the radiological classification reaches category 2 simple pneumoconiosis or more. The Committee consider that an automatic assumption of disability should no longer be made although there is no hint that men already receiving a pension should lose it. They consider that it is possible to have pneumoconiosis without measurable disablement and that such men should be seen regularly so that a pension could be awarded if measurable disability did develop. Furore followed this pronouncement. A minority dissenting view was published by the same member who disagreed about the question of bronchitis.

The historical background to this difficulty is referred to in the report and merits a short summary in this review. Some 50 years ago it was evidently thought that the ravages of 'miners' asthma' (i.e., dyspnoea) had been conquered by improved ventilation underground and that coal mine dust was harmless. These surprising conclusions were based on inadequate epidemiological data which did not expose the severe health problems associated with the expanding coal fields of South Wales. In due course, however, the true state of affairs became obvious and the Medical Research Council began a detailed survey of respiratory diseases in South Wales coal miners. Their conclusions were published in 1942 and showed beyond doubt that coal mine dust could and did cause a disabling form of pneumoconiosis which was quite different from silicosis. The earliest stages appeared to form a reticular pattern on the radiograph. This was therefore termed the stage of $x$-ray reticulation and corresponds to the early stages of simple pneumoconiosis of coal workers in the modern classification. Improved techniques now show that the radiological reticulation is really made up of small nodules and the term has fallen into disuse.

The MRC report stated that the early stages of pneumoconiosis appeared to indicate a pulmonary condition which may cause disability but that a considerable proportion of such men would have no detectable disability at the time of examination. Herein lies the crux of the matter. If a miner is diagnosed by the Pneuomconiosis Medical Panel as having definite evidence of the disease (i.e., category 2 or more) should an automatic presumption be made that he is likely to be disabled to the extent of at least $1 \%$ ? The Industrial Injuries Advisory Council (1953) decided that this was a reasonable assumption and their recommendations form the basis of current compensation practice. The Council reversed this decision in the present report after hearing evidence from many sources and stated that 'We are satisfied that, in so far as simple pneumoconiosis of coal workers meets the definition of pneumoconiosis under the Act, it is not in general a cause of appreciable disability and does not appreciably affect life expectancy'. They recommend that an automatic prescription of disability should not be made but that cases should be kept under observation until there is assessable disablement.

The report does not say what assessable disablement is. The omission is crucial. Presumably it must be a $1 \%$ drop in some function associated with breathing or respiration.

Mr. Evans has an FEV 1 of 2,980 ml. The "normal predicted' value for his age and height is $3000 \mathrm{ml}$ and therefore he does not qualify for a $1 \%$ disability rating. Mr. Jones, being of the same age and build, does qualify because his $F E V_{1}$ is only $2960 \mathrm{ml}$. The mind boggles.

It is quite clear that this line of thought leads nowhere. A recent epidemiological survey carried out under the direction of the Chief Medical Officer of the National Coal Board (Rogan et al., 1973) gives information of crucial importance on the relationship between radiological abnormality and respiratory disability. The survey demonstrated that dust exposure is associated with a fall in ventilatory capacity, that it is also associated with radiological changes in some men, but that such changes do not appear to be associated with any further change in FEV 1 . In the population studied it is apparent that, on average, a man with category 2 or 3 pneumoconiosis has been exposed to about twice as much dust as men whose radiographs were classified as category 0 . The regression equations show that such dust exposure is associated with a fall in $F^{2} V_{1}$ which is beyond question greater than $1 \%$ of the mean for men whose radiological category is 0 . This is the evidence that is required. It is clear that radiological evidence of category 2 or 3 pneumoconiosis implies a measurable disability in a group of men. It is logical to suggest that the same implication is likely to apply to individuals within the group. Individual variations undoubtedly occur and some men in the group may have suffered no drop in $\mathrm{FEV}_{\mathbf{1}}$ nor in any other test of lung function currently available. However, the onus of proving that such a disability has not occurred in a single man must surely be placed on those who deem it appropriate to withhold compensation. Whatever the motives of the Secretary of State for Social Services in rejecting these recommendations he appears to have had solid grounds for doing so.

A further point concerning 'reticulation' deserves note. The origin of radiological reticulation has been discussed above. Pathologists have also described dust-reticulation. This refers to an increase in reticulin tissue associated with coal dust retention and which is visible on histological sections. This was the 'reticulation' implied by the current definition of pneumoconiosis and has nothing whatever to do with the radiological appearances. The Council recommend that the term should be dropped al- 
together in the future so that misunderstanding may be avoided.

It is unlikely that the matter will rest. In the further controversy ahead the report will form a valuable document for those who take part and the hard work of the Committee has not been wasted.

\section{References}

Department of Health and Social Security (1973). Pneumoconiosis and Byssinosis. Report by the Industrial Injuries Advisory Council in accordance with Section 62 of the National Insurance (Industrial Injuries) Act, 1965 on Pneumoconiosis and Byssinosis. Cmnd. 5443. HMSO, London.
Medical Research Council (1942). Chronic Pulmonary Disease in South Wales Coalminers. 1. Medical Studies. Special Report Series No. 243. HMSO, London.

Report of the Industrial Injuries Advisory Council (1953). Raynaud's Phenomenon. Cmnd. 8866. HMSO, London.

Rogan, J. M., Attfield, M. D., Jacobson, M., Rae, S., Walker, D. D., and Walton, W. H. (1973). Role of dust in the working environment in development of chronic bronchitis in British coal mines. British Journal of Industrial Medicine, 30. 217-226.

Received for publication 25 May 1974. Accepted for publication 30 June 1974.

\title{
Occupational health and safety in Great Britain 1972
}

\author{
R. A. TREVETHICK \\ British Steel Corporation
}

When reviewing the several reports concerned with safety and health at work for 24 million employed people in the United Kingdom one is immediately struck by the differences of presentation rather than the similarities; from the thick glossy to the thin paper-back; and a lack of uniformity in the statistical tables.

For example, it took some time to assemble the figures on injuries in the following Table, and even so comparisons are only approximate which adds

\begin{tabular}{|c|c|c|c|c|c|c|c|}
\hline \multirow{2}{*}{\multicolumn{2}{|c|}{ Place of work }} & \multirow{2}{*}{ No. of workers } & \multicolumn{2}{|c|}{ Fatal accidents } & \multicolumn{2}{|c|}{ Reportable injuries } & \multirow{2}{*}{$\begin{array}{l}\text { Reportable } \\
\text { diseases }\end{array}$} \\
\hline & & & Total & Per 100000 & Total & Per 100000 & \\
\hline $\begin{array}{ll}\text { Factories } & \ldots \\
\text { Agriculture } & \ldots \\
\text { Shipping } & \ldots \\
\text { Coal mines } & \ldots \\
\text { Quarries } & \ldots \\
\text { Shops and offices }\end{array}$ & $\begin{array}{l}\cdots \\
\cdots \\
\cdots \\
\cdots \\
\cdots\end{array}$ & $\begin{array}{r}14000000 \\
700000 \\
90000 \\
297000 \\
? \\
8000000\end{array}$ & $\begin{array}{r}468 \\
118 \\
113 \\
72 \\
36 \\
30\end{array}$ & $\begin{array}{c}3 \cdot 3 \\
17 \\
125 \\
24 \\
? \\
0 \cdot 3\end{array}$ & $\begin{array}{r}258000 \\
5711 \\
- \\
77000 \\
3217 \\
18000\end{array}$ & $\begin{array}{c}1843 \\
814 \\
- \\
25700 \\
? \\
225\end{array}$ & $\begin{array}{r}274 \\
25 \\
134 \\
3256 \\
? \\
-\end{array}$ \\
\hline Totals .. & . & 23087000 & 837 & & 361928 & & \\
\hline
\end{tabular}

